\title{
Divulgación científica: enseñanza y evaluación
}

\author{
Erick Daniel Cruz Mendoza
}

\section{Resumen}

La perspectiva pedagógica de la comunicación de la ciencia invita a reflexionar cuestiones relacionadas con la enseñanza y el aprendizaje. En la divulgación científica este tema genera discusión y causa posturas contrastantes acerca de la evaluación de los divulgadores, los productos y los públicos. Estas cuestiones se exponen en el presente trabajo con el propósito de brindar un panorama de la actividad divulgativa desde el enfoque educativo.

Palabras clave: comunicación de la ciencia, educación formal, educación no formal, educación informal.

\section{SCientific Dissemination: teaching and evaluation}

\begin{abstract}
The pedagogical perspective on science communication encourages a critical reflection on education and learning related topics. However, the research on scientific dissemination generates contrasting positions about the evaluation process of science communicators, products and audiences. This article examines these matters to provide an outlook on the science communicator's work from an educational perspective.
\end{abstract}

Keywords: science communication, formal education, non-formal education, informal education.

DOI: http://doi.org/10.22201/codeic.16076079e.2019.v20n4.a3 


\section{Erick Daniel Cruz Mendoza}

http://orcid.org/0000-0001-9632-2319 cm.erick18@gmail.com

Licenciado en ciencias de la comunicación por la Universidad del Mar y diplomado en divulgación científica (Centro Interdisciplinario de Investigación para el Desarrollo Integral Regional, Unidad Oaxaca, Instituto Politécnico Nacional). Interesado en temas de comunicación de la ciencia, agencias de noticias y cultura digital. Actualmente realiza una investigación sobre las habilidades digitales de los universitarios en contextos de pobreza digital.

\section{Introducción}

Existen diversas maneras para nombrar a las actividades relacionadas con la comunicación de la ciencia, en Iberoamérica se utilizan los términos: divulgación científica, difusión científica, periodismo científico y comunicación pública de la ciencia (Tagüeña, Rojas y Reynoso, 2006). Aunque todas ellas coinciden con el objetivo de llevar la ciencia al público, cada una tiene sus propias herramientas, intenciones y funciones. Sin embargo, el hecho de compartir un mismo objeto - el sistema tecnocientífico- las hace difíciles de diferenciar.

La modalidad que interesa revisar en este texto es la divulgación científica, pues cuando se habla de este tema emergen una variedad de opiniones y posturas acerca de su conceptualización y funciones. Al respecto, Sánchez (2010) entrevé la necesidad de formar un consenso para establecer las bases de la divulgación en la actualidad, pues se desconocen numerosas situaciones de la ciencia y, por ende, de esta modalidad para transmitir conocimiento.

Actualmente todavía se conceptualiza la divulgación de la ciencia como una

${ }^{1}$ No todas son malas noticias, en años recientes se dio un aumento en la oferta de diplomados y actividades relacionadas con la capacitación en sedes distintas a la Universidad Nacional Autónoma de México

(UNAM): Diplomado en Comunicación de la ciencia (Morelos, 2015), el diplomado en Comunicación de la ciencia

y Periodismo científico (Morelos, 2016) y el diplomado de Divulgación científica divertida (Oaxaca, 2018), entre otros. actividad de especialistas (científicos, profesores, comunicadores, entre otros) de diferentes ámbitos (ciencias naturales y ciencias sociales) que comparten el interés en el área. Es decir, a pesar de su más de medio siglo de operación, la divulgación no es considerada como una profesión. ${ }^{1}$

A la divulgación científica se le ha llamado de otras formas, en ocasiones es común escuchar los enunciados: alfabetización de la ciencia, agrupación social del conocimiento científico y popularización de la ciencia. La adaptación del término depende de diversos factores, uno de ellos y quizá el más importante es la constante evolución del campo de la divulgación, luego están las características culturales, sociales y demográficas.

Las aproximaciones conceptuales realizadas en torno a la divulgación (Estrada, 1992; García, 2008; Sánchez, 2010) convergen en algunos aspectos: la divulgación va dirigida a un público no especializado, se presenta en varios formatos (presenciales y no presenciales), se emplea un lenguaje coloquial o accesible y es un acto voluntario del público. 
Figura 1. Divulgación científica: taller (actividad presencial con mediador).
${ }^{2}$ Al hablar de educación formal nos referimos al sistema educativo jerarquizado, cronológicamente graduado, que va desde la primaria hasta la universidad. En cambio, la educación no formal es cualquier otra actividad organizada fuera del sistema educativo. La educación informal, por su parte, se relaciona con los procesos a lo largo de toda la vida a través de los cuales cada individuo adquiere actitudes, valores, destrezas y conocimientos de la experiencia diaria (Coombs, Prosser y Ahmed, 1973, cit. en Pastor, 2001).

3 "El profesor Peter Medawar atribuye a Gombrich la invención del término mesianismo científico para designar la posición que considera a la ciencia como la única fuente del conocimiento humano, como el último árbitro de la moral y de la ética, como la solución de todos los problemas que aquejan a la humanidad" (Pérez, 1991: 38).
Debido a lo anterior, se piensa que la divulgación se ubica entre los límites de la educación no formal y la educación informal. ${ }^{2}$ Esta reflexión conlleva al problema central en la educación: la evaluación. En ese sentido, en la divulgación existen dos posturas, una en donde se argumenta la necesidad de evaluar al divulgador, a los productos divulgativos y al público y, otra, en donde se dicta lo contrario.

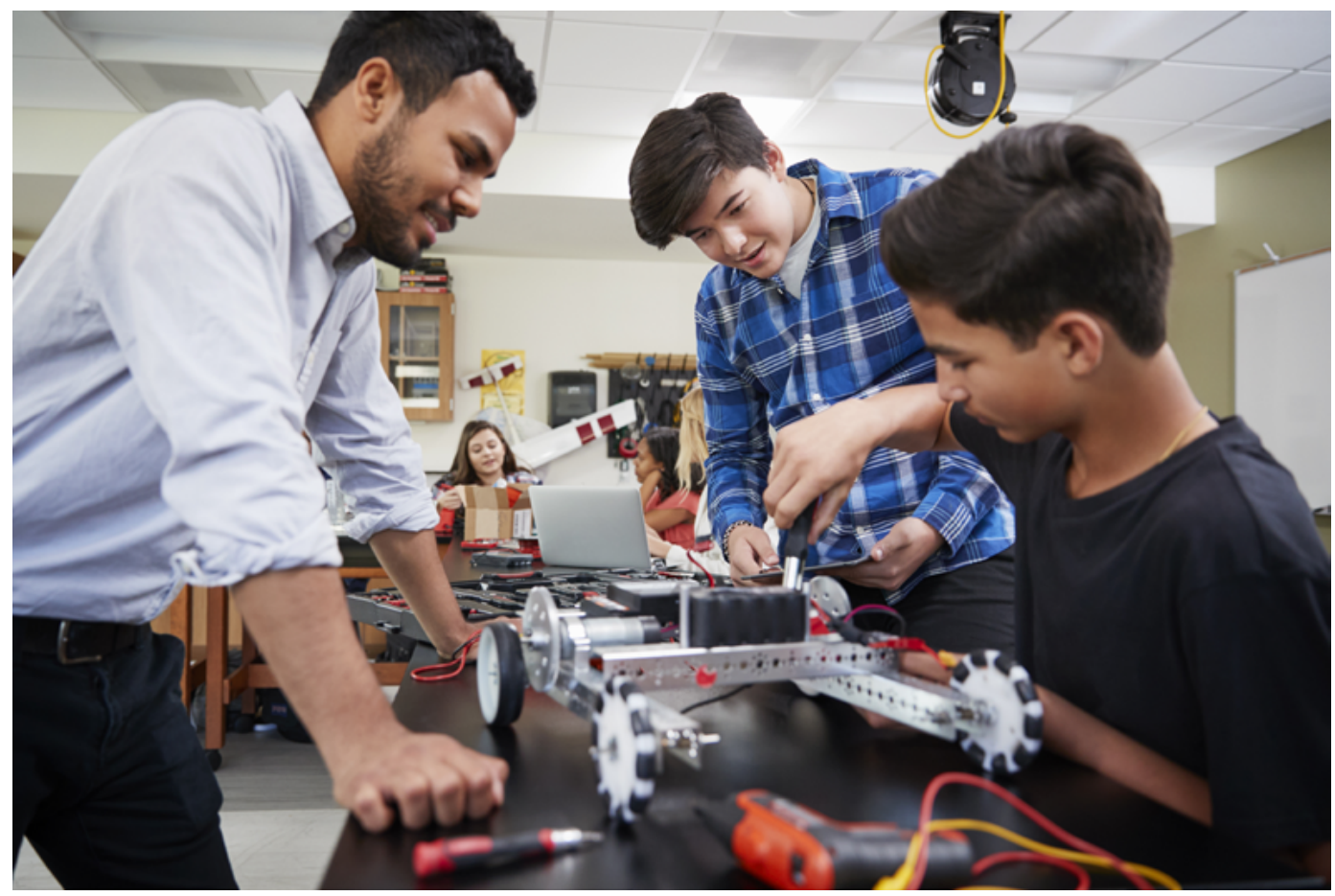

Otro de los temas centrales a la hora de hablar de ciencia es la enseñanza. Ziman (1972) da cuenta de la relación entre la actividad científica y la enseñanza a partir de la propuesta del conocimiento público, la cual, conlleva a reflexionar los procesos en donde el conocimiento pasa de una generación a la siguiente. Es decir, el científico en su faceta de profesor recrea los elementos de su investigación para explicarlos a sus estudiantes. Para Ziman la educación basada en el conocimiento consensible, es decir, comunicado y validado por la comunidad científica, pone al estudiante en un campo intelectual común con los científicos, lo que le permite trabajar a la par de ellos. Pero ¿qué pasa con aquellos sujetos situados al margen de la educación formal deseosos por aprender los conocimientos brindados por la ciencia?

Esta discusión demuestra la necesidad de comunicar la ciencia a públicos no especializados o sin formación académica en ciencias (naturales o sociales). En este contexto, es pertinente señalar que al hablar de la importancia del conocimiento científico en la vida del hombre no se pretende exponer a la ciencia como la panacea para sanar los males del mundo entero, tampoco se le declara como la única fuente del conocimiento humano de la forma que lo hace el mesianismo científico. ${ }^{3}$ 
En realidad, la intención es pensar a la ciencia como una actividad humana - con sus aciertos y errores-, cuyos productos se hacen públicos con el fin de hacer del mundo un lugar mejor. Tal y como lo expuso Medawar al presentar al mejorismo científico ${ }^{4}$ como una alternativa ante el dogma.

Siguiendo la premisa anterior, relacionada con la necesidad de comunicar la ciencia de persona en persona o de generación en generación, Anita Woolfolk explora la idea de la educación como un "proceso por el cual la sociedad transmite sus valores, creencias, conocimientos y sistemas simbólicos a todos sus miembros" (cit. en Patiño, 2013: 39). Desde esta óptica, el conocimiento científico puede llegar a las personas a través de — por lo menos - tres formas: la educación formal, la educación no formal y la educación informal.

\section{Construyendo el trinomio educativo para comunicar la ciencia}

Las autoras Carmen Sánchez Mora y Guillermina De Francisco (2013) coinciden en que la divulgación es una labor educativa ${ }^{5}$ en donde la educación no formal e informal se presentan como una alternativa para la formación científica de las personas excluidas de la educación formal, por ello vale la pena discurrir las diferencias y similitudes entre cada una de estas vías.

Para definir los conceptos citados anteriormente las autoras recurren

4 "Un mejorista es simplemente quien cree que el mundo puede ser un lugar mejor [...] gracias a una acción humana sabiamente emprendida; los mejoristas, además, creen que pueden emprenderla [...] Los mejoristas son personas comparativamente humildes que tratan de hacer el bien y son felices al comprobar que esto se ha logrado" (Medawar cit. en Pérez, 2010: 237).

5 Para llegar a esta conclusión las autoras diferenciaron los términos: educación, divulgación, enseñanza y aprendizaje. Consideran que educación es un proceso general que engloba a los procesos particulares de enseñanza y aprendizaje, mientras la divulgación es una labor educativa en tanto comunica el conocimiento científico, sus valores y sistemas simbólicos a los miembros de la sociedad. a la propuesta de Coombs, Prosser y Ahmed, quienes manifestaron una terminología educativa para discutir las formas no convencionales de educación. Los resultados son las siguientes definiciones tomadas del artículo "Orígenes y evolución del concepto de educación no formal" de María Inmaculada Pastor Homs:

Al hablar de educación informal nos referimos exactamente al proceso a lo largo de toda la vida a través del cual cada individuo adquiere actitudes, valores, destrezas y conocimientos de la experiencia diaria y de las influencias y recursos educativos de su entorno - de la familia y vecinos, del trabajo y el juego, en el mercado, la biblioteca y en los medios de comunicación.

La educación formal significa, desde luego, el sistema educativo jerarquizado, estructurado, cronológicamente graduado, que va desde la escuela primaria hasta la universidad, e incluye, además de los estudios académicos generales, una variedad de programas especializados e instituciones para la formación profesional y técnica a tiempo completo.

[...] definimos la educación no formal como cualquier actividad educativa organizada fuera del sistema formal establecido - tanto si opera independientemente o como una importante parte de una actividad más amplia- que está orientada a servir a usuarios y objetivos de aprendizaje identificables (Coombs, Prosser y Ahmed, 1973 citado en Pastor, 2001: 527).

A manera de síntesis se enlistan brevemente las características de los procesos de educación (formal, no formal e informal) para dar cuenta de las discrepancias y semejanzas encontradas entre los tres tipos: 
Tabla 1. Procesos efectuados en la educación formal, no formal e informal.

Fuente: elaboración propia con base en información de Sánchez Mora, C. y De Francisco, Guillermina (cit. en Patiño, 2013: 39-55).

\begin{tabular}{|l|c|c|c|}
\hline \multirow{2}{*}{ Ítems } & \multicolumn{3}{|c|}{ Tipos de educación } \\
\cline { 2 - 4 } & $\begin{array}{c}\text { Educación } \\
\text { formal }\end{array}$ & $\begin{array}{c}\text { Educación no } \\
\text { formal }\end{array}$ & $\begin{array}{c}\text { Educación } \\
\text { informal }\end{array}$ \\
\hline $\begin{array}{l}\text { Procesos con intención } \\
\text { educativa }\end{array}$ & $\bullet$ & $\bullet$ & \\
\hline $\begin{array}{l}\text { Inclusión en el sistema } \\
\text { educativo (legal) }\end{array}$ & $\bullet$ & $\bullet$ & \\
\hline $\begin{array}{l}\text { Tiene metas educativas } \\
\text { claras y definidas }\end{array}$ & $\bullet$ & $\bullet$ & \\
\hline $\begin{array}{l}\text { Es conducida por personal } \\
\text { calificado }\end{array}$ & $\bullet$ & $\bullet$ & \\
\hline Dirigida a público general & $\bullet$ & $\bullet$ & \\
\hline $\begin{array}{l}\text { Dirigida a público } \\
\text { especializado }\end{array}$ & & $\bullet$ & \\
\hline $\begin{array}{l}\text { Implica un acto voluntario } \\
\text { del receptor }\end{array}$ & & $\bullet$ & \\
\hline $\begin{array}{l}\text { Efectuada durante el } \\
\text { tiempo libre }\end{array}$ & & & \\
\hline $\begin{array}{l}\text { Satisface necesidades } \\
\text { específicas }\end{array}$ & & & \\
\hline
\end{tabular}

Desde la educación éstas son las vías para comunicar cualquier tipo de conocimiento o saber acerca del mundo. Por ejemplo, ¿quién recuerda cómo aprendió a manejar bicicleta? Se puede asegurar que ninguna persona fue a una escuela de manejo en donde le enseñaron reglas para el equilibrio y el balance $y$, al final, le otorgaron un título profesional. En cambio, a partir de la educación informal los padres ayudaron a sus hijos a practicar el manejo de la bicicleta: sus consejos para perder el miedo son esenciales.

Con el paso del tiempo aquellos niños crecieron y surgieron dudas que sus padres o amigos no podían resolver. Y para responder por qué la Tierra es esférica acudieron a los museos de ciencia o planetarios, en donde los astrónomos y físicos - mediante la educación no formal- les explicaron que si se paran a la orilla de la playa y ven un barco ocultándose en el horizonte del mar lo primero en desaparecer es la cubierta, luego, el mástil y al final, el humo. Esto porque la Tierra es esférica, si fuera plana el barco desaparecería de mayor a menor escala.

Sin embargo, en la escuela —educación formal—, el profesor explicó que la forma esférica del planeta se debe a la fuerza de gravedad, la cual atrae con igual intensidad de todas las direcciones hacia el centro, por ello la superficie irregular del planeta poco a poco se ha ido compactando en forma de esfera. 
Figura 2. Museo de Mañana, museo de ciencias de Río de Janeiro, Brasil. Fuente: istockphoto .

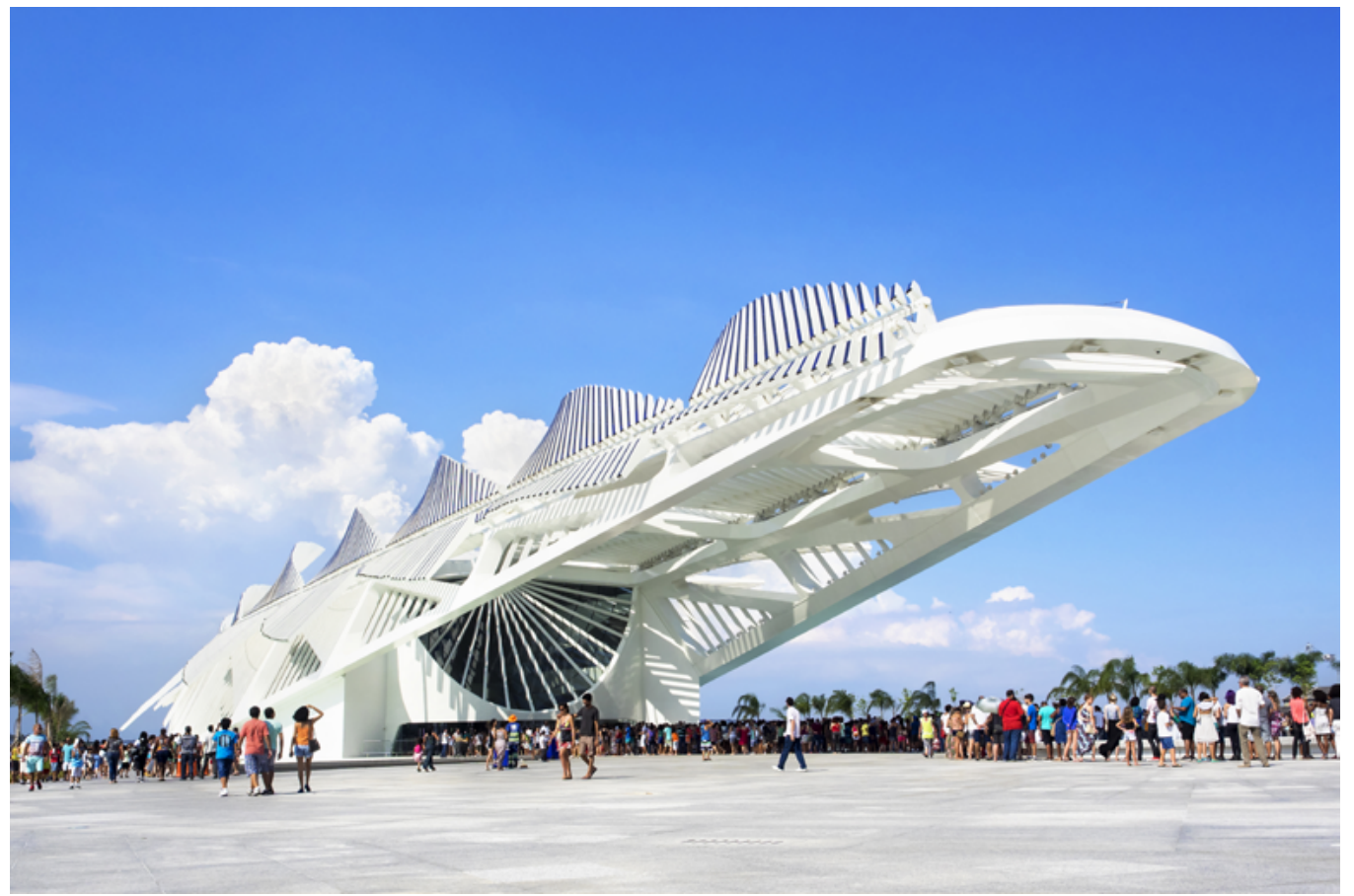

A pesar de los esfuerzos por diferenciar estos conceptos, para De Francisco y Sánchez (2013), las categorías divisorias de la educación (formal, no formal e informal) no tienen bien definidos sus límites, pues, no consideran una relación y jerarquía lógica. Estas complicaciones llevan a los autores a replantear nuevos esquemas para explicar las relaciones funcionales entre estas categorías, añadiendo al análisis las relaciones de complementariedad, de suplencia, de substitución, de refuerzo y colaboración y de interferencia.

\section{La evaluación en la divulgación científica}

Al observar a la divulgación desde una mirada pedagógica surgen interrogantes relacionadas con la evaluación. Por un lado, existen grupos que conciben a este ejercicio como una herramienta para mejorar el accionar de los divulgadores y la calidad de sus productos. Mientras, por el otro, se excusa este enjuiciamiento por representar una "barrera" ante la creatividad.

Estas son algunas cuestiones con las cuales trabajan los divulgadores en la actualidad. Dentro de este contexto, Reynoso (2008) distingue dos posturas claramente marcadas: en una se encuentran aquellos que se oponen a la evaluación anteponiendo la libertad creativa, mientras, en el otro extremo, están quienes plantean esquemas muy estructurados para la evaluación de productos y de sus realizadores.

La comunicación de la ciencia y en específico, la divulgación científica va ganando terreno en la oferta de consumo cultural, lo cual se refleja en la 
6 Es una revista mensual de la Dirección General de Divulgación de la Ciencia

de la UNAM que se publica ininterrumpidamente desde diciembre de 1998. Es la única revista de divulgación científica en el país dirigida específicamente a lectores jóvenes (de bachillerato y primeros años de licenciatura). Sus lectores son mujeres y hombres de 14 a 39 años de edad, con ingresos medios; sobre todo estudiantes, profesores y trabajadores de empresas en el sector privado. Para mayor información consultar http://www.comoves.unam. $\mathrm{mx} / \mathrm{somos}$. exigencia por construir herramientas que ayuden a evaluar la calidad de los emisores-mensajes-receptores con el propósito de mejorarlos. Por ejemplo, Magaña (2008) describe la evaluación de la divulgación científica en la Facultad de Ciencias de la Universidad Nacional Autónoma de México (UNAM), en donde se proponen una serie de lineamientos que deben cumplir las diversas actividades efectuadas (relacionar la ciencia con problemas naturales y sociales, proporcionar información suficiente para el análisis, presentar las implicaciones éticas, políticas y sociales del quehacer científico, entre otras). Esto les permite emitir criterios al evaluar la continuidad de los proyectos.

No es fácil medir la eficacia del trabajo de divulgación, ya que los impactos de ello sólo pueden estimarse, y por ello la evaluación de la misma en la Facultad de Ciencias tiene, a pesar de su mejora, muchos aspectos subjetivos. Pero al igual que otros sistemas, los hasta ahora usados tienen que ver con número y calidad e impacto (medido en forma indirecta) (Magaña, 2008: 134).

Los parámetros implementados varían dependiendo la naturaleza de las actividades divulgativas, es decir, para medir el éxito de las conferencias y exposiciones se emplean medidas como el conteo de asistentes y los comentarios recuperados por escrito. En cuanto a los medios masivos de comunicación se toma en cuenta el interés de la prensa en dar espacios a los divulgadores ya sea de manera presencial o por medio de colaboraciones.

En el caso de la divulgación científica escrita, se han realizado investigaciones para conocer la opinión de los lectores sobre este tipo de materiales. Tonda y Burgos (2007) realizaron un estudio de opinión sobre la revista ¿Cómo ves?6, mediante el cual recuperaron información que contribuyó a conocer el perfil de los lectores e identificar sus gustos. En años más recientes se han ensayado propuestas de evaluación de la divulgación científica centradas en la percepción del público. Campillo (2015) diseñó una metodología para evaluar textos divulgativos en formato digital sobre biotecnología. Las categorías que ponderan dicha metodología son: público, registro lingüístico, discurso del texto, extensión, temporalidad gramática, rigor, plagio y recursos (presentación). A este ejemplo se suma la reciente publicación de la Guía de valoración de la actividad de divulgación científica del personal académico e investigador (2018), en donde se presentan índices de calidad para evaluar los aportes del emisor en la comunicación de la ciencia con el objetivo de valorar el currículo de investigadores y maestros en su labor de productor de libros, artículos, exposiciones y creación de materiales, entre otros.

Bajo este panorama, Jensen (2014) plantea una serie de problemas en la evaluación de la comunicación de las ciencias, en donde pone en evidencia las debilidades del diseño metodológico implementado por diversos museos y ferias de ciencias al momento de evaluar el éxito de sus actividades. El autor, sugiere que una buena evaluación de la comunicación de la ciencia requiere de una planificación de objetivos por parte de los practicantes, además, de la formación de los evaluadores en métodos actuales de investigación social. 
Figura 3. ¿Cuáles son los criterios para evaluar la calidad de la divulgación científica? Fuente: istockphoto
Luego de revisar ambas posturas se concluye que la evaluación es necesaria en el quehacer divulgativo porque ayuda a conocer los aciertos y errores. Una manera de saber si se tiene éxito es partir de la valoración que brindan los colegas y los usuarios. Así, la divulgación entendida como un acto de comunicación en donde se enseña-aprende se compone por: emisor, mensajes y receptor. Todavía no se sabe con exactitud cómo sería una evaluación adecuada de éstos, ni qué parámetros se deben tomar en cuenta. No obstante, es menester hacer algunas recomendaciones.

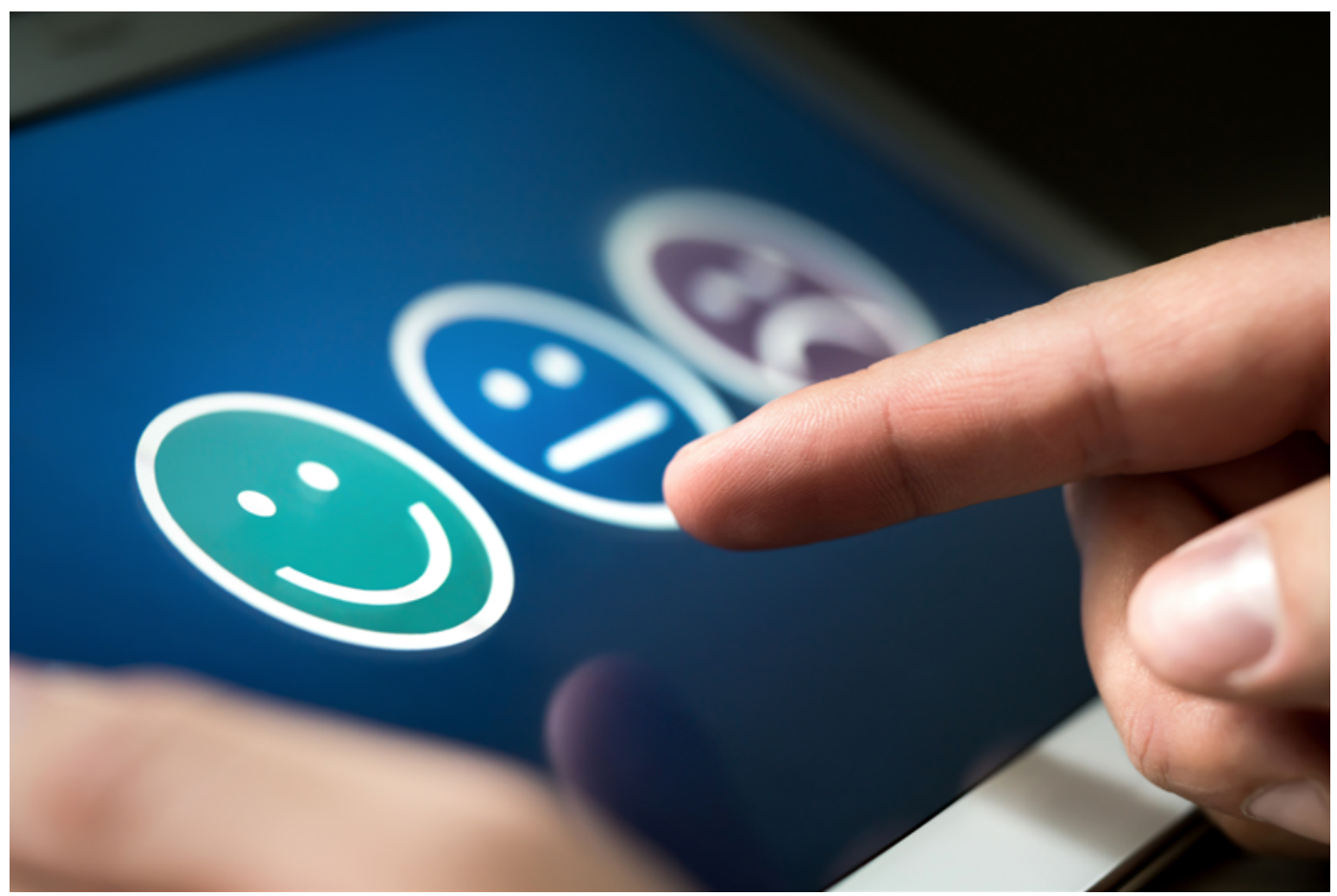

De entrada, se puede asegurar que lo fiable para el divulgador es recibir una evaluación de la voz de sus colegas y del público. En cuanto al mensaje, la evaluación depende del tema abordado y del medio empleado. Es decir, el contenido está sujeto a la crítica de los especialistas. Por otra parte, el medio (soporte) brinda el marco de normatividad que otorga el estatus de calidad del producto.

El receptor, a diferencia de los emisores y los mensajes, no puede ni debe ser evaluado en términos positivos o negativos. Sin embargo, él sí puede opinar acerca del divulgador y del contenido. En la actualidad, se realizan estudios en donde se evalúa el aprendizaje de los consumidores de productos divulgativos para saber si éstos están teniendo éxito. También, hay encuestas de percepción pública de la ciencia en donde se señalan los medios y temas mayormente consumidos.

La caracterización de los tres tipos de educación sirve para brindar un panorama general sobre cómo se comunica el conocimiento. No obstante, existe un debate en torno a la evaluación del aprendizaje en la educación. En la evaluación 
${ }^{7}$ En el mes de junio de este año, Recreación en Cadena "Red Mexicana de Talleristas de Ciencia" en conjunto con el Consejo Nacional de Ciencia, Tecnología e Innovación (CONACYT), la UNAM, Universum Museo de Ciencias, Museo

de Ciencias UAZ, entre otras instituciones y organizaciones, celebraron

el $4^{\circ}$ Coloquio Nacional de Ciencia Recreativa "Evaluación de las actividades de ciencia recreativa", en donde uno de los ejes temáticos es "Evaluación de los talleres de ciencia recreativa", donde se discutieron criterios y modelos analíticos para medir el éxito de las actividades, los individuos y los grupos dedicados a la divulgación recreativa de la ciencia. se reconocen - por lo menos - dos actores involucrados: evaluador (emisor del conocimiento) y evaluado (receptor del conocimiento). En la educación formal la evaluación suele ser periódica y tiene repercusiones negativas o positivas para el evaluado. Para realizar esta valoración se utilizan herramientas como el examen de diagnóstico y las pruebas de aprendizaje. Al respecto,

\begin{abstract}
parece evidente que si un profesor cree que el aprendizaje es una actividad memorística opte por unos criterios de evaluación centrados básicamente en la cantidad de conocimiento y en la fidelidad de la información reproducida, así como que formule demandas que impliquen procesos cognitivos como la memorización, el reconocimiento o el recuerdo. La información así obtenida se limita a los aspectos del aprendizaje más fácilmente cuantificables, pero difícilmente permitirá conocer si el alumno es capaz de pensar de manera crítica sobre el contenido. Por el contrario, si se considera la evaluación como parte del proceso de enseñanza y aprendizaje, durante el proceso, la cesión progresiva del control del profesor al alumno permite que los criterios de evaluación y la evaluación en sí misma pasen a adquirir una función reguladora, que faciliten la identificación de los aspectos relevantes, que permitan establecer prioridades y dirigir las actividades en un sentido concreto (Pérez y Carretero, 2009: 97).
\end{abstract}

De esta manera se contraponen dos puntos de vista en la evaluación de la educación formal, en donde es necesario brindar resultados para continuar con los programas de estudio de cualquier institución formativa. No obstante, en la educación no formal e informal emerge una barrera al momento de intentar valorar el aprendizaje de los públicos.

Sólo por mencionar, la divulgación de la ciencia es una actividad voluntaria y por ende no está sujeta a una evaluación de aprendizaje como sí se hace en la educación escolarizada. Entonces, ¿es necesario realizar una evaluación del aprendizaje de los contenidos científicos para mejorar las actividades? Si la respuesta es sí, ¿cómo se evalúa el aprendizaje de los públicos en la divulgación? En consecuencia, de estas preguntas surge otro reto: ¿es necesario evaluar a los divulgadores? ${ }^{7}$

\section{Conclusiones}

Las visiones apolítica vs integrada -analogía de Eco- de la evaluación en la divulgación científica se presentan como un oxímoron de contradicciones, es decir, hay propuestas en donde se evalúa un componente de la divulgación emisores - y se pasan por alto otros - mensaje y receptores-. Al final, estas perspectivas deben converger para evaluar a la divulgación científica desde una perspectiva global, considerando la unicidad de cada una de las experiencias y productos que se crean al realizar esta labor.

Anteriormente se expusieron algunas metodologías implementadas para medir el éxito de la divulgación ofertada en diferentes formatos y por diversas instituciones. Sin embargo, estamos conscientes en que no son todas las utilizadas en la actualidad, por ello, se sugiere a los divulgadores hacer 
públicas las estrategias de evaluación implementadas en el día a día para construir herramientas sólidas que contribuyan a mejorar esta modalidad de comunicación de la ciencia.

Además, en la actualidad, con el uso de las tecnologías de la información y el internet, cada vez son las más los espacios virtuales de aprendizaje informales en donde las personas consumen contenidos de ciencia y tecnología. Esto ha sido detectado por los divulgadores, quienes ahora desarrollan propuestas de canales divulgativos por temáticas en plataformas como YouTube, en donde las métricas para medir el acceso a los contenidos se basan en el número de suscriptores, el tráfico y el tiempo de reproducción. No obstante, cabe preguntarse si estos ítems garantizan la calidad de los contenidos.

Sin duda en el contexto de la cultura digital surgen otras problemáticas para la evaluación de la divulgación científica, empero, para dar el siguiente paso en la construcción de este campo es necesario atender a las dificultades precedentes. Para finalizar, es indispensable continuar con este tipo de investigaciones pedagógicas porque brindan certidumbre a la actividad divulgativa, la cual, se hace presente cada vez más en nuestras vidas.

\section{Referencias}

* Campillo, S. (2015). Evaluación de la calidad de la divulgación científica aplicada a la biotecnología en los medios digitales (tesis de Máster en Biología Molecular y Biotecnología). Universidad de Murcia, España.

* Sánchez Mora, Carmen y De Francisco, Guillermina (2013). Educación no formal. En Patiño, B. (Coord.), La divulgación de la ciencia en México desde distintos campos de acción: Visiones, retos y oportunidades (pp. 39-60). México: Sociedad Mexicana para la Divulgación de la Ciencia y la Técnica, A.C. Recuperado de: http://www. redpop.org/wp-content/uploads/2015/06/divulgacion mexico somedicyt.pdf.

* Estrada, L. (1992). La divulgación de la ciencia. Ciencias, 27, 69-76. Recuperado de: http://www.revistaciencias.unam.mx/images/stories/Articles/27/CNS02713.pdf.

* FECYT. (2018). Guía de valoración de la actividad de divulgación científica del personal académico einvestigador. España: Fundación Española para la Cienciay la Tecnología. Recuperado de: https://www.upo.es/diario/wp-content/uploads/2018/12/GuiaValoraci\%C3\%B3n-Divulgaci\%C3\%B3n-CRUE-FECYT.pdf.

* García, M. (2008). Ciencia en todos los rincones: manual de divulgación en talleres. México: Universidad Autónoma de Zacatecas, Coordinación de Investigación y Posgrado.

Jensen, E. (2014). The problems with science communication evaluation. Journal of Science Communication, 13, 1-3. Recuperado de: https://jcom.sissa.it/archive/13/01/ JCOM 13012014 C04. 
* Magaña, P. (2008). La evaluación de las actividades de divulgación en la Facultad de Ciencias de la Universidad Nacional Autónoma de México. En Lozano, M. y Sánchez, C. (Coords.), Evaluando la Comunicación de la ciencia: una perspectiva latinoamericana. Memorias de las Jornadas Iberoamericanas sobre Criterios de Evaluación de la Comunicación de la Ciencia (pp. 131-138). Cartagena, Colombia. Recuperado de: http://www.redpop.org/wp-content/uploads/2015/06/Evaluandola-comunicacin-de-la-ciencia.pdf.

* Pastor, l. (2001). Orígenes y evolución del concepto de educación no formal. Revista española de pedagogía, 220, 525-544. Recuperado de: https://www.jstor.org/ stable/23765896? seq=1\#page scan tab contents.

* Patiño, B. (2013). La divulgación de la ciencia en México desde distintos campos de acción: Visiones, retos y oportunidades. México: Sociedad Mexicana para la Divulgación de la Ciencia y la Técnica, A.C. Recuperado de: http://www.redpop. org/wp-content/uploads/2015/06/divulgacion mexico somedicyt.pdf.

* Pérez, M. y Carretero, M. (2009). La evaluación del aprendizaje en la educación secundaria: análisis de un proceso de cambio. Límite, 19, 93-126. Recuperado de: http://www.redalyc.org/articulo.oa?id=83611433005.

* Pérez, R. (1991). Ciencia, paciencia y conciencia. México: Siglo Veintiuno Editores.

* Pérez, R. (2010). Reflexiones sobre la ciencia. México: El Colegio Nacional.

* Reynoso, E. (2008). La evaluación de los comunicadores de la ciencia: una perspectiva mexicana. Razón y Palabra, 65. Recuperado de: http://www.redalyc. org/articulo.oa?id=199520724007.

- Reynoso, E. (2016). Historia y perspectivas de la comunicación pública de la ciencia en México. En la conferencia XV aniversario del grupo de divulgación científica Quark, del Museo de Ciencias de la Universidad Autónoma de Zacatecas (UAZ), el 29 de agosto de 2016.

* Sánchez,A.(2010). Introducción a la comunicaciónescrita delaciencia. Veracruz, México: Universidad Veracruzana, Dirección General Editorial. Recuperado de: http://depa. fquim.unam.mx/amyd/archivero/Introduccionaladivulgacionescrita 26664.pdf.

* Tagüeña, J., Rojas, C. y Reynoso, E. (2006). La divulgación de la ciencia en México en el contexto de la América Latina. En Ponencia presentada el Primer Congreso Iberoamericano de Ciencia, Tecnología, Sociedad e Innovación CTS+ I. México D. F. (Vol. 19).

* Tonda, J. y Burgos, E. (2007). Análisis y evaluación de las revistas de divulgación. Proceedings of the x Reunión de la Red de Popularización de la Ciencia y la Tecnología en América Latina y el Caribe (RED POP-UNESCO) y IV Taller 'Ciencia, Comunicación y Sociedad', San José, Costa Rica, 9-11. Recuperado de: http://www.cientec.or.cr/ pop/2007/MX-JuanTonda.pdf.

- Ziman, J. M. (1972). El conocimiento público: Un ensayo sobre la dimensión social de la ciencia. México: Fondo de Cultura Económica [trabajo original publicado en 1968]. 


\section{Cómo citar este artículo}

- Cruz Mendoza, Erick Daniel (2019). Divulgación científica: enseñanza y evaluación. Revista Digital Universitaria (RDU). Vol. 20, núm. 4 julio-agosto. Dol: http://doi. org/10.22201/codeic.16076079e.2019.v20n4.a3.

Recepción: 11/12/2018 Aprobación: 14/05/2019. 